\title{
Correction to: Life cycle efects of technology on revenue in the music recording industry 1973-2017
}

\author{
Ivan L. Pitt ${ }^{1}$
}

Published online: 25 November 2020

(c) Springer Nature Switzerland AG 2020

\section{Correction to: SN Bus Econ (2021) 1:9 \\ https://doi.org/10.1007/s43546-020-00004-x}

An error was made in the author's affiliation. This has now been correct to read: Independent Senior Economist and Data Scientist.

The original article can be found online at https://doi.org/10.1007/s43546-020-00004-x.

Ivan L. Pitt

ipitt@att.net

1 Independent Senior Economist and Data Scientist, New York, NY, USA 